\title{
EMERÊNCIA DO PROFESSOR ANTONIO BARROS DE CASTRO*
}

\author{
Ricardo Bielschowsky ${ }^{* *}$
}

É um prazer e uma honra estar participando desta homenagem ao amigo e professor Antonio Barros de Castro, um dos grandes acadêmicos que a Universidade Federal do Rio de Janeiro teve em toda sua história. Parabenizo o Conselho Universitário pela decisão, agradeço o convite a meu amigo e reitor Aloisio Teixeira, na pessoa de quem cumprimento os demais professores e os ex-professores, alunos e ex-alunos presentes. Saúdo também os convidados, e muito especialmente os familiares, a esposa Ana Célia, os filhos Nando, Isabel, Ana Clara e Lavinia, e o genro Alexandre.

I. Atributos do Castro como acadêmico: Já que se trata de um momento de reconhecimento, a ocasião permite que eu comece assinalando alguns dos atributos do Castro como professor e intelectual:

a) Inteligência. Trata-se de uma mente privilegiada, brilhante, que está sempre agregando construções analíticas engenhosas ao debate brasileiro. Castro é um argumentador incisivo, por escrito e no debate oral. Isso aparece de formas distintas, por exemplo, nas discussões com os pares intelectuais, ou na transmissão do conhecimento aos alunos, na forma respeitosa e fecunda que usa para fazer o aluno pensar, ou ainda nos artifícios que emprega para atrair alunos e colegas àquilo que considera a raiz do problema discutido, e de habilmente atraí-los a seu campo teórico.

b) Criatividade e ousadia. No seu compromisso com a aquisição e com a transmissão de conhecimento, Castro abre grande espaço e liberdade à imaginação. Existe uma saborosa entrevista com ele publicada em um livro chamado Conversas com os economistas, onde diz o seguinte: "Por influência seguramente de Popper, na minha visão de mundo o "faro" e a "sensibilidade" contam muito no avanço do conhecimento. A lógica e os dados servem para questionar. O que produz é a imaginação". Ao mesmo tempo, Castro combina ousadia e criatividade com rigor acadêmico, é meticuloso no uso de ideias e de dados.

\footnotetext{
* Discurso realizado na cerimônia de entrega do título de Professor Emérito da Universidade Federal do Rio de Janeiro (UFRJ) a Antonio Barros de Castro, em dezembro de 2008.

** Professor licenciado do Instituto de Economia da UFRJ.
} 
c) Assiduidade, perseverança, profissionalismo. A inteligência e a imaginação são os famosos $10 \%$, o resto é transpiração. Nem sempre é fácil tirar o Castro de sua biblioteca, ele deve a muitos de seus amigos um tempinho para ir jogar uma sinuca ou dar um "pulo" na praia ou no boteco para bater um papo.

d) Entusiasmo. O compromisso, talvez excessivo, com o trabalho é pelo menos, em parte, compensado por outro atributo, o trabalho intelectual que lhe dá muito prazer. Castro é um intelectual entusiasmado: tem a sede de conhecimento, própria dos grandes acadêmicos e cientistas, transmite uma alegria contagiante com reflexões bem formuladas, com novas descobertas. Valoriza isso de uma forma absolutamente humanista, o saber e a ciência são vistos como fonte essencial do progresso humano.

e) Vasta cultura, erudição em história, principalmente a econômica (mas também nos campos político, social e cultural), e especialmente erudição em história do Brasil. Poucos conhecem o Brasil como Castro. E erudição em teoria econômica. Não se fazem mais professores assim.

f) Método. De todos os atributos, o que mais nos encanta é seu método analítico, que reside na combinação entre "história" e "teoria", entre o momento do conhecimento empírico e o momento da formulação analítica: a história alimenta a teorização e a teoria facilita a interpretação da história. É a chamada "história pensada", analisada, interpretada, em um diálogo permanente entre a observação das tendências históricas e a teorização sobre elas.

Para o método contribuíram, aparentemente, dois momentos básicos em sua formação. Primeiro, depois de se formar em 1959, aqui mesmo na UFRJ - menciona como seus principais e "notáveis" mestres, nesta universidade, Bulhões, Campos, Santiago Dantas, e Dias Leite, aqui presente - foi estudar filosofia em Londres. Passou um ano por lá discutindo história da ciência, método científico, epistemologia. Preparou-se para o exercício da profissão nesse momento. De carona, estudou métodos quantitativos em Paris, algo que sempre ajuda.

Segundo, quando voltou ao Brasil, foi trabalhar com Anibal Pinto no escritório da Comissão Econômica para a América Latina e o Caribe (CEPAL), junto à Maria da Conceição Tavares e Carlos Lessa. Pode-se bem imaginar o entusiasmo e a criatividade intelectual naquele encontro na CEPAL, no início dos anos 1960 entre essas quatro inteligências privilegiadas. Castro abraçou então, o que talvez seja o grande ativo do estruturalismo, o método histórico-estrutural. O método permite a interação entre o enfoque dedutivo e o histórico-interpretativo, faz uma espécie de heurística positiva: parte de uma teorização sobre o subdesenvolvimento periférico latino-americano, mas está o tempo todo atento às trajetórias dos agentes e das instituições, a 
suas especificidades, e à vida política e social dos países, o que permite retornar à formulação teórica e alterá-la em forma permanente. É um método voltado ao movimento, à transformação.

II. Passo agora à trajetória extraordinária de Castro nos dois trilhos sobre os quais se movem a vida acadêmica: o de professor, e o de pesquisador. Antes, quero assinalar algumas características dessa trajetória.

a) Preferências teóricas. Sem hierarquizar, elas incluem Marx (leis de movimento, lei da tendência, das crises, o Marx do desequilíbrio como algo normal, intrínseco à operação do capitalismo) Keynes, Schumpeter (e mais recentemente os economistas contemporâneos da área de inovação, como Penrose e Nelson), Hirschmann (também pelo lado da importância do desequilíbrio) e, entre os estruturalistas, Prebisch, Furtado e Anibal Pinto. Economista essencialmente "não teórico", "aplicado". Do ponto de vista teórico é um heterodoxo eclético, mas é essencialmente um usuário da teoria econômica para fins da análise dos processos de transformação econômica e social no capitalismo brasileiro. Sua obra é, no essencial, profundamente engajada na vida brasileira. O Brasil tem essa virtude de se discutir, de estar sempre com toda uma intelectualidade refletindo sobre seus problemas. Eu sou uma espécie de colecionador dessa reflexão na área do desenvolvimento econômico. Pois bem, o Castro é um dos mais atentos e atuantes protagonistas dessa vida intelectual.

b) Otimismo histórico. Castro tem a convicção de que a organização social e política dos cidadãos do país conta para o curso da história, de que as forças de mercado por si só não conseguem desenvolver o país, de que a organização social e política pode acionar o Estado para cumprir tarefas centrais em um projeto de transformação; faz oposição ferrenha ao determinismo histórico do fracasso, e é otimista no entendimento de que o capitalismo brasileiro tem importantes elementos de dinamismo, que devem ser aproveitados em uma estratégia social-democrata de crescimento com redistribuição de renda.

c) Nacionalismo. Castro é um nacionalista, no melhor sentido da expressão: um defensor da melhoria de vida da população do Brasil, da beleza de sua cultura, da beleza e da integridade de seu território, mas com profundo respeito pelo restante da humanidade, e pela soberania e melhoria de vida de cada nação. O empenho pelas coisas do Brasil representa uma forma de valorização, pela diversidade, do ser humano em todo o mundo, é um nacionalismo também humanista, universalista.

d) Polemizador. Castro é um debatedor por natureza, e um refutador de dogmas - prazerosamente, quando se opõe à direita, ao pensamento neoliberal, e meio sem jeito, mas com determinação, quando os dogmas vêm da esquerda. Ao mesmo tempo, é corajoso em concordar, sem preconceitos 
ideológicos, com intelectuais em qualquer posição ideológica, à sua direita ou à esquerda, quando acha justo e importante.

III. Todos esses atributos se revelam em suas aulas e em seus escritos, que marcaram a vida de inúmeros alunos. A trajetória como professor, no Brasil e no exterior, inclui centralmente seis ou sete disciplinas:

a) Na CEPAL lecionou duas disciplinas: Introdução à Economia, que herdou de Osvaldo Sunkel e Anibal Pinto, e Estilos de capitalismo, herdada de Anibal Pinto, que versa sobre a importância da história e da política na geração de capitalismos diferenciados (como o inglês, o americano, o japonês, e o italiano).

b) Na UFRJ (na segunda metade dos anos 1960) lecionou outras duas: Teoria dos Ciclos, e Economia Brasileira.

c) No Chile, durante alguns anos, voltou às experiências de desenvolvimento comparadas: Inglaterra, Estados Unidos, Japão, China e União Soviética, e além disso lecionou cursos sobre Economia Marxista.

d) Em Campinas, entre 1974 e 1976, continuou com os cursos sobre marxismo, baseados nos volumes 1 e 3 de $O$ Capital.

e) Anos depois foi para a COPPE, da UFRJ onde lecionou cursos sobre economia brasileira.

f) Em seguida fez o concurso e entrou como titular na Faculdade de Economia e Administração (FEA $)^{1}$ da UFRJ, e passou a lecionar principalmente dois cursos. Inicialmente Economia Brasileira e, posteriormente, com a frustração do Cruzado e o entendimento de que a inflação não permitia o desenvolvimento, voltou-se para a macroecomomia, e lecionou cursos sobre Política Econômica (monetária, fiscal, cambial).

Formou, portanto, várias gerações de economistas. Quem teve o privilégio de ser seu aluno, aprendeu com o curso, sobretudo, com o método e com o estímulo que ele transmitiu para a aquisição do conhecimento.

IV. Passo, finalmente, a sua trajetória como pesquisador. Produziu dezenas de livros e artigos. Não é o caso aqui de percorrê-los um a um, de modo que vou mencionar algumas obras, ou seja, as que se transformaram ou que tendem a transformar-se em referência obrigatória na bibliografia brasileira.

Entre os mais importantes, dois não são estritamente ligados ao seu compromisso com o debate e a construção de estratégias nacionais correntes.

\footnotetext{
${ }^{1}$ Antiga denominação do Instituto de Economia da UFRJ, que incluía também a Faculdade de
} Administração. 
Um é o livro-texto Introdução à Economia, o famoso Castro-Lessa, o texto sobre economia, talvez mais lido no Brasil, publicado em meados da década de 1960. Foi um "manual” encomendado por Anibal Pinto, para os cursos da CEPAL, com grande poder didático. Tinha vendido mais de 500 mil cópias há cerca de 10 anos. Isso, no Brasil, é tiragem de livro de ficção, não de texto técnico, acadêmico.

O segundo é um trabalho de pesquisa histórica sobre o engenho de açúcar do século XVII, em que estuda as inovações técnicas e o comportamento dos senhores de engenho. Nesse trabalho, polemiza com os principais historiadores do período: não é verdade que não havia progresso técnico na escravidão no Nordeste, o engenho de açúcar era uma empresa quase capitalista, etc.

A maioria dos demais textos básicos de Castro é engajado no debate nacional e teve grande impacto no pensamento brasileiro. Tornaram-se referência e mostraram a aderência com a história corrente e um profundo envolvimento na discussão sobre o desenvolvimento no Brasil, no contexto e no calor de diferentes conjunturas econômicas e ideológicas. São obras historicamente determinadas, quase nos detalhes. Os principais textos ou conjuntos de textos são: Sete ensaios sobre a economia brasileira, O capitalismo ainda é aquele, A economia brasileira em marcha forçada, Desenvolvimento por consumo de massa, e o texto Renegade development, é da safra mais recente, voltada à questão da inovação. Vou destacar essencialmente a motivação do mestre ao elaborar os textos.

O livro Sete ensaios sobre a economia brasileira, produzido na segunda metade dos anos 1960, tem por temáticas centrais a agricultura e o desenvolvimento regional, e é conscientemente voltado à polêmica. Já em sua orelha se lê: "Este livro tem subentendidas certas posições que, consciente ou inconscientemente, são rejeitadas pela maioria daqueles que vêm escrevendo sobre nossa história e nossos problemas econômicos"; ou o seguinte alerta sobre a perversidade do modelo brasileiro: "Estes ensaios procuram (...) demonstrar que o sistema econômico no Brasil tem sido capaz de expandir-se indefinidamente sem reformas sociais - o que implica dizer que os problemas sociais não estão sendo convertidos em problemas econômicos pela evolução da história” (ele quer dizer aqui, por exemplo, que a pobreza de parte da agricultura não está impedindo a expansão agrícola, e que a má distribuição de renda não está impedindo a acumulação capitalista e a expansão econômica - ou seja, que o modelo funciona, só que é perverso). 
O livro tem uma curiosidade: só tem seis ensaios. O sétimo não foi publicado, era sobre o modelo perverso, e acabou tornando-se supérfluo porque naquela época foi publicado o excelente texto de Conceição e Serra Além da estagnação contendo a ideia de que o capitalismo podia crescer sem desconcentração de renda e, mais ainda, que a concentração, então em curso, estaria sendo funcional ao crescimento.

Vinte anos depois Castro voltaria à questão da ligação entre crescimento e distribuição de renda. Fez isso em um texto de 1988, em que fala da viabilidade de um modelo de consumo de massa no Brasil. A sequência da produção dessa ideia tem cinco etapas.

Primeiro, no início dos anos 1960, Furtado assinalou que o crescimento brasileiro tendia a conservar o subemprego. Segundo, em meados dos anos 1960, o mesmo Furtado elaborou um esquema analítico brilhante - mas o apresentou com um defeito. O brilhantismno estava, por um lado, na integração entre o perfil da oferta de bens e a composição setorial dos investimentos e da produção e, por outro, entre o perfil distributivo e o de consumo. A concentração de renda no Brasil estaria determinando certo perfil produtivo em setores modernos semelhante ao dos países desenvolvidos; porém, enquanto nesses países o resultado é certa homogeneidade produtiva e social, no Brasil, o modelo - destinado a uma minoria da população - é pouco absorvedor de mão de obra e concentrador de renda, acirrando a heterogeneidade produtiva e social. O defeito na formulação de Furtado foi a conclusão de que isso condena a economia à estagnação, por retornos decrescentes de escala, e que a única saída para a estagnação seria redistribuir a renda e alterar o modelo de investimento, produção e crescimento. Com o crescimento a partir de 1967 a tese foi ultrapassada pelos fatos.

O terceiro momento foi quando Conceição e Serra disseram, em Além da estagnação, que, infelizmente, a concentração de renda estava sendo funcional ao crescimento, que o modelo era perverso, mas funcionava, era dinâmico. A quarta etapa ocorreu quando pesquisadores como John Wells, João Saboia e outros usaram dados da Pesquisa de Orçamentos Familiares (POF) e da Pesquisa Nacional por Amostra de Domicílios (PNAD) e mostraram que os pobres têm elevada propensão a consumir bens produzidos nos setores modernos.

A quinta etapa se iniciou com Castro, em 1988. Diante das evidências do Cruzado comprovando essa propensão, ele assinalou que a estrutura diversificada já montada se prestava, também, a um modelo de crescimento com redistribuição de renda, pela via do consumo de massa. Ou seja, redistribuir 
a renda não significa aposentar a estrutura produtiva a duras penas montada no país. Isso foi usado depois pelo Partido Trabalhista (PT) em campanhas eleitorais e foi incorporado nos Planos Plurianuais 2004-2007 e 2008-2011.

\section{O engajamento do Castro tem mais alguns momentos analiticamente refinados e politicamente provocativos. Cito, para terminar, quatro deles.}

1. Por exemplo, o livro O capitalismo ainda é aquele, escrito no final dos anos 1970. Esse é o livro que saiu como amadurecimento do debate sobre a natureza do capitalismo brasileiro (discutia-se muito isso nos anos 1970 no Brasil, capitalismo dependente, capitalismo perverso, capitalismo de estado, capitalismo tardio, etc). Castro escreveu o livro à luz da conjuntura econômica de meados dessa década e nos anos que se seguiram. Contém um texto denominado "Por que não Kalecki”. Não tinha a discordância com a esquerda de que o capitalismo tem crises, mas para ele cada crise tem sua especificidade e ocorre em forma caótica, sem temporalidade definida. Discordava, por essa razão, da tese de oscilações cíclicas regulares, com base no modelo formalizado por Kalecki: inflexão cíclica não é teorizável por modelos, as rupturas são idiossincráticas. Além disso, não concordava com uma série de autores que defendiam que o Brasil estivesse vivendo em meados dos anos 1970 uma tendência à baixa dos investimentos, uma reversão cíclica, e que isso estaria sendo apenas contrarrestado por conta de investimentos estatais, em uma política contracíclica de cunho keynesiana. Castro (com base, por exemplo, em Tugan Baranovski) considerava que os investimentos da fase do II Plano Nacional do Desenvolvimento (PND) eram um desdobramento natural dos investimentos da fase do I PND, e que os setores de infraestrutura e de insumos básicos eram a bola da vez, e eram perfeitamente capazes de dar o impulso necessário à continuidade ao crescimento.

2. Alguns anos depois veio o livro A economia brasileira em marcha forçada. Também é um livro datado, é parte de seu engajamento. No debate da primeira metade dos anos 1980 havia a consciência da profundidade da crise, mas também esperança em uma superação que permitisse a retomada do desenvolvimento econômico. Castro vinha argumentando, por volta de 1983, que a moratória era viável, fez as contas e concluiu que havia como enfrentar a comunidade financeira internacional e crescer com moratória. Veio, então, a surpresa de 1983/1984: um saldo súbito e gigantesco na balança de pagamentos, que ele examinou com cuidado, junto a um exímio pesquisador do comércio externo brasileiro, o Francisco Eduardo Pires de Souza. Chegaram à conclusão de que se tratava de um saldo estrutural - e, portanto que, ainda que viável, a moratória era desnecessária. E mostrava com isso que o estrangulamento externo que sempre castigou a economia 
brasileira havia se atenuado por força daquilo que os estruturalistas e desenvolvimentistas sempre argumentavam ser o mecanismo de superação do estrangulamento, ou seja, a própria industrialização brasileira. Os dados mostravam que os investimentos do II PND, conduzidos pelo ministro Velloso haviam viabilizado isso, bastou uma recuperação da economia mundial para que os efeitos dos investimentos se revelassem.

3. Outro texto poderoso - infelizmente, pouquíssimo conhecido - surgiu em 1993, em inglês, sobre a criação e a dissolução de uma convenção do crescimento (o título é Renegade development). A ideia é, primeiro, a de que a era desenvolvimentista se beneficiou de uma vontade nacional de fazer crescer a economia, que se expressava em pressões políticas fortes que empurravam os governos na direção de decisões de investimento ousadas e de expansão econômica; e, segundo, que a crise dos anos 1980 e a fragilização do desenvolvimentismo deu lugar a uma superação da convenção do crescimento. É um artigo que o professor Castro quer há 15 anos expandir e transformar em livro. Um texto nada otimista, que lamenta a fragilização do Estado desenvolvimentista e da ideologia desenvolvimentista. Quem sabe, a verdadeira razão por que Castro não tem conseguido retomar o tema é o fato de que a interpretação é pouco assimilável por seu espírito otimista.

4. Por último, estão os artigos de uma nova etapa, iniciada há 10 anos (de orientação penrosiana), no tema comportamento empresarial e inovação: identificação de importantes vocações e energias diferenciadas nos agentes produtivos no país, e necessidade de mobilização dos "recursos nacionais". Talvez o texto mais importante da safra atual é o que argumenta sobre a viabilidade plena de recuperação do crescimento rápido e sustentável, publicado em 2005. A ideia é a de que não há mais razões macroeconômicas e nem institucionais que impeçam a retomada do crescimento em longo prazo. É o Castro estruturalista, de volta ao otimismo. Entre as preocupações mais recentes, não por acaso, estão trabalhos sobre a China e sobre o petróleo, entendidos como dois elementos novos fundamentais na discussão de um futuro padrão de desenvolvimento no Brasil.

VI. Posso falar em nome de todos os presentes, e de todos os professores desta casa: nós temos orgulho do Castro, somos orgulhosos de pertencer a uma Universidade que o tem como professor. 